\title{
The Growth of Pseudomonas AM1 on 4-Hydroxybutyrate
}

\author{
By R. B. COX AND J. R. QUAYLE \\ Department of Microbiology, University of Sheffield, Sheffield SIo $2 T N$
}

(Received I6 July 1976)

\section{INTRODUCTION}

Previous reports of bacterial growth on 4-hydroxybutyrate and 4-aminobutyrate by respectively a Pseudomonas sp. (Nirenberg \& Jakoby, 1960) and Clostridium amiuobutyricum (Hardman, 1962) have indicated that these substrates are metabolized by initial conversion to succinate via succinic semialdehyde, using NAD-linked dehydrogenases. The present work indicates the operation of a similar route during growth of Pseudomonas AMI on 4-hydroxybutyrate, except that the initial dehydrogenation is effected by the primary alcohol dehydrogenase (PAD) of the organism rather than an NAD-linked enzyme. Possible implications of this with respect to growth of the organism on substrates such as ethanol, malonate and 3-hydroxybutyrate are discussed.

\section{METHODS}

A mineral salts medium (Jayasuriya, I955), containing filter-sterilized growth substrates at a concentration of $0.2 \%$, was used as the growth medium; organisms were grown and crude (bacteria-free) extracts were prepared as described by Cox \& Quayle (1976). Streptomycin-resistant strains of mutant MI5A were prepared, from which spontaneous revertants to growth on methanol and to growth on 4-hydroxybutyrate were isolated using methods previously described (Cox \& Quayle, 1976).

Primary alcohol dehydrogenase [alcohol dehydrogenase (acceptor) EC. I. I.99.8] was assayed at $30{ }^{\circ} \mathrm{C}$ both spectrophotometrically, as described by Anthony (1971), in the presence of 5 mM-methanol or 33 mm-sodium 4-hydroxybutyrate (Sigma), and by manometric assay by following oxygen uptake. Manometer flasks contained (total vol., $3 \mathrm{ml}$ ): $300 \mu \mathrm{mol}$ Tris $/ \mathrm{HCl}$ buffer, $\mathrm{pH} 8.0 ; 45 \mu \mathrm{mol} \mathrm{NH}_{4} \mathrm{Cl}$; $10 \mu \mathrm{mol}$ methanol or $100 \mu \mathrm{mol}$ 4-hydroxybutyrate; enzyme. Reactions were started by mixing with $3.3 \mu \mathrm{mol}$ phenazine methosulphate contained in the side bulb. The centre well contained $0.1 \mathrm{ml} 5 \mathrm{M}-\mathrm{NaOH}$.

\section{RESULTS AND DISCUSSION}

Pseudomonas AMI grows on sodium 4-hydroxybutyrate with a mean doubling time of about $\mathrm{I} 5 \mathrm{~h}$; 4-aminobutyrate does not support growth. We have been unable to detect any NAD- or NADP-linked 4-hydroxybutyrate dehydrogenase in crude extracts prepared from the 4-hydroxybutyrate-grown organism. Such extracts did however have a high specific activity of PAD (Table I). PAD activity measured using the spectrophotometric assay was lower when 4-hydroxybutyrate was used as the substrate instead of methanol. However, the manometric assay showed unequivocally that crude extracts of Pseudomonas AM I grown on either methanol or 4-hydroxybutyrate oxidized 4-hydroxybutyrate and that oxidation depended on phenazine methosulphate and $\mathrm{NH}_{4} \mathrm{Cl}$. After the exhaustion of endogenous 
Table I. Specific activities of primary alchohol dehydrogenase in crude extracts of Pseudomonas AMI and mutants

PAD was measured spectrophotometrically with methanol as substrate.

$\begin{array}{llc}\text { Organism } & \text { Growth substrate } & \begin{array}{c}\text { Specific activity } \\ \text { [nmol min }\end{array} \\ \left.\text { Pseudomonas }\left(\mathrm{mg}^{-1} \text { protein }\right)^{-1}\right]\end{array}$

substrate present in crude extracts, the steady rate of oxygen uptake with 4-hydroxybutyrate was about $25 \%$ of that with methanol. MI5A, a mutant of Pseudomonas AMI unable to grow on methanol and deficient in PAD activity (Heptinstall \& Quayle, 1970), did not grow on 4-hydroxybutyrate. Revertants of MI5A isolated on methanol medium all grew on 4-hydroxybutyrate, similarly all revertants isolated on 4-hydroxybutyrate grew on methanol. Both types of revertant were found to have regained PAD activity.

These results indicate that the oxidation of 4-hydroxybutyrate (presumably to succinic semialdehyde) in Pseudomonas AMI is catalysed by the PAD first described in methanolgrown Pseudomonas M27 by Anthony \& Zatman (1964a, b) and since found in a wide

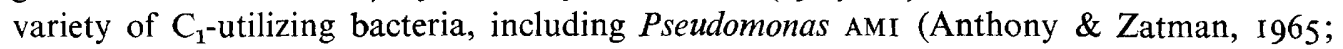
Anthony, 1971, 1975; Sperl, Forrest \& Gibson, 1974). The enzyme has a wide substrate specificity for primary alcoholic groups. The proximity of a charged group to the hydroxyl group is clearly an important factor in determining whether the hydroxy compound is a substrate for the enzyme. Thus Sperl et al. (1974) have shown that Io-hydroxydecanoic acid is oxidized by PAD whereas glycollic acid (2-hydroxyacetic acid) is not; they did not test 4-hydroxybutyric acid and it is not known at what intermediate chain length substrate activity appears. Surprisingly, PAD purified as described by Anthony (I97I) from either methanol or 4-hydroxybutyrate-grown organisms failed, in manometric experiments, to catalyse the oxidation of substrate amounts of 4-hydroxybutyrate although methanol was oxidized to completion. Since crude extracts of the organism oxidized 4-hydroxybutyrate under the same experimental conditions there may be some additional electron transport component present in crude extracts which is involved in the dehydrogenation of 4-hydroxybutyrate but not of methanol.

The use of PAD for metabolism of such different substrates as methanol and 4-hydroxybutyrate is an interesting demonstration of the metabolic diversity that possession of this enzyme may confer on an organism. There is however another possible implication of these findings with respect to the two routes of carbon assimilation which have been proposed for the growth of Pseudomonas AMI on 3-hydroxybutyrate, ethanol and malonate (Cox \& Quayle, 1976; Taylor \& Anthony, 1976); one of these routes involves a coupling of malyl-CoA lyase with malyl-CoA hydrolase giving an overall malate synthase activity. The reactions involved in the alternative route are obscure although this route must also involve the net production of a $\mathrm{C}_{4}$ molecule from two $\mathrm{C}_{2}$ units. In view of the metabolism of 4-hydroxybutyrate by PAD, an enzyme which is synthesized by the organism during growth on 3-hydroxybutyrate (Table 1 ), an attractive possibility is that the alternative route might 
involve the formation of 3 -hydroxybutyrate, its isomerization to 4-hydroxybutyrate and subsequent conversion to succinate via succinic semialdehyde. Although we have so far been unable to demonstrate the isomerization of 3-hydroxybutyrate or 3-hydroxybutyrylCoA in extracts of 3-hydroxybutyrate-grown PCT57 and ICT5IR, mutants of Pseudomonas AMI which use the alternative pathway for $C_{2}$ assimilation (Cox \& Quayle, 1976), the implications of any such interconversion which may be observed in future work should be borne in mind.

We acknowledge financial support from the Science Research Council under grant no. B/RG/27I I 8 .

\section{REFERENCES}

Anthony, C. (1971). Prosthetic group of an alcohol dehydrogenase of a Pseudomonad. Methods in Enzymology 18B, 808-813.

ANTHONy, C. (I975). The cytochromes of Pseudomonas AMr. Biochemical Journal 150, 569-571.

Anthony, C. \& Zatman, L. J. (1964a). Isolation and properties of Pseudomonas sp. m27. Biochemical Journal 92, 609-6I4.

Anthony, C. \& Zatman, L. J. (1964b). The methanol-oxidizing enzyme of Pseudomonas sp. M27. Biochemical Journal 92, 6I 4-621.

Anthony, C. \& Zatman, L. J. (1965). The alcohol dehydrogenase of Pseudomonas sp. m27. Biochemical Journal 96, 808-8I 2.

Cox, R. B. \& QUAYLE, J. R. (1976). Synthesis and hydrolysis of malyl-coenzyme A by Pseudomonas AMI : an apparent malate synthase activity. Journal of General Microbiology 95, I 2 I-I 33.

HARDMAN, J. K. (I 962). $\gamma$-Hydroxybutyrate dehydrogenase from Clostridium aminobutyricum. Methods in Enzymology 5, 778-783.

Heptinstall, J. \& QUayle, J. R. (I 970). Pathways leading to and from serine during growth of Pseudomonas AMI on $C_{1}$ compounds or succinate. Biochemical Journal $117,563-572$.

JAYASURIYA, G. C. N. (1955). The isolation and characteristics of an oxalate-decomposing organism. Journal of General Microbiology 12, 419-428.

NirenberG, M. W. \& JAKOBY, W.B. (I960). Enzymatic utilization of $\gamma$-hydroxybutyric acid. Journal of Biological Chemistry 235, 954-960.

Sperl, G. T., Forrest, H. S. \& GibSon, D. T. (1974). Substrate specificity of the purified primary alcohol dehydrogenases from methanol-oxidizing bacteria. Journal of Bacteriology 118, 54I-550.

TAYLOR, I. J. \& ANTHONY, C. (1976). Acetyl-CoA production and utilization during growth of Pseudomonas AMI on ethanol, malonate and 3-hydroxybutyrate. Journal of General Microbiology 95, 134-143. 